Pacific Journal of Mathematics

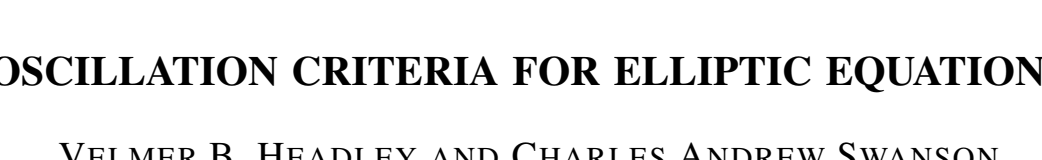




\title{
OSCILLATION CRITERIA FOR ELLIPTIC EQUATIONS
}

\author{
V. B. Headley and C. A. Swanson
}

Conditions on the coefficients of a linear elliptic partial differential equation will be obtained which are sufficient for the equation to be oscillatory in certain unbounded domains. The criteria obtained in the first three theorems involve integrals of suitable majorants of the coefficients while the criterion in Theorem 4 involves limits of these majorants at infinity. We also obtain a nonoscillation criterion involving similar limits.

Oscillation criteria of both limit type and integral type will be obtained for the linear elliptic partial differential equation

$$
L u \equiv \sum_{i, j=1}^{n} D_{i}\left(a_{i j} D_{j} u\right)+b u=0
$$

in unbounded domains $R$ in $n$-dimensional Euclidean space $E^{n}$. Our theorems constitute extensions of several well-known one-dimensional oscillation theorems of Kneser-Hille [6] (limit type), Leighton [8], Moore [10], and Wintner [13] (integral type). A special case of Theorem 4 below was obtained by Glazman [4,5] when $L$ is the Schrödinger operator and $R$ coincides with $E^{n}$. Analogues of Theorem 1 were obtained by Kreith [7] and Swanson [12] in the case that one variable is separable and $R$ is limit cylindrical, i.e., contains an infinitely long cylinder.

Points in $E^{n}$ are denoted by $x=\left(x^{1}, x^{2}, \cdots, x^{n}\right)$ and differentiation with respect to $x^{i}$ is denoted by $D_{i}, i=1,2, \cdots, n$. The functions $a_{i j}$ and $b$ involved in (1) are assumed to be real-valued and continuous on $R \cup \partial R$, and the matrix $\left(a_{i j}\right)$ is supposed to be symmetric and positive definite in $R$ (ellipticity condition). A "solution" of (1) is defined in the usual way $[1,12]$.

We assume that $R$ contains the origin and that $R$ is large enough at $\infty$ in the $x^{n}$ direction to contain the cone $C_{\alpha}=\left\{x \in E^{n}: x^{n} \geqq|x| \cos \alpha\right\}$ for some $\alpha, 0<\alpha \leqq \pi$. The boundary $\partial R$ of $R$ is supposed to have a piecewise continuous unit normal vector at each point. The following notations will be used:

$$
R_{r}=R \cap\left\{x \in E^{n}:|x|>r\right\} ; \quad S_{r}=\{x \in R \cup \partial R:|x|=r\} .
$$

A bounded domain $N \subset R$ is said to be a nodal domain of a nontrivial solution $u$ of (1) if and only if $u=0$ on $\partial N$. The differential equation (1) is said to be oscillatory in $R$ if and only if there exists a nontrivial solution $u_{r}$ of (1) with a nodal domain in $R_{r}$ for 
all $r>0$. It follows from the $n$-dimensional analogue of Sturm's separation theorem [1] that every solution of an oscillatory differential equation vanishes at some point in $R_{r}$ for all $r>0$.

Let $\wedge(x)$ denote the largest eigenvalue of the matrix $\left(a_{i j}(x)\right)$, $x \in R$. A majorant of $\left(a_{i j}\right)$ is a positive-valued function $f \in C^{1}(0, \infty)$ such that

$$
f(r) \geqq \max _{x \in S_{r}} \wedge(x) \quad(0<r<\infty) .
$$

The function $g$ defined by

$$
g(r)=\min _{x \in S_{r}} b(x) \quad(0<r<\infty)
$$

is called a majorant of $b(x)$.

Let $A, B$ be the functions in $R$ defined by the equations $A(x)=f(|x|)$, $B(x)=g(|x|)$, respectively. We shall obtain oscillation theorems for equation (1) by comparing (1) with the separable equation

$$
\sum_{i=1}^{n} D_{i}\left(A D_{i} v\right)+B v=0 .
$$

Let $r, \theta_{1}, \theta_{2}, \cdots, \theta_{n-1}$ denote hyperspherical polar coordinates [9, p. 58], defined as follows:

$$
\left\{\begin{array}{l}
x_{1}=r \prod_{i=1}^{n-1} \sin \theta_{i}, \quad x_{n}=r \cos \theta_{1}, \\
x_{i}=r \cos \theta_{n-i+1} \prod_{j=1}^{n-i} \sin \theta_{j}, \quad i=2,3, \cdots, n-1 .
\end{array}\right.
$$

By writing (3) in terms of these coordinates, we find that (3) has solutions (in particular) of the form

$$
v(x)=\rho(r) \varphi\left(\theta_{1}\right), \quad 0 \leqq r<\infty, \quad 0 \leqq \theta_{1} \leqq \alpha,
$$

where $\rho$ and $\varphi$ satisfy the ordinary differential equations

$$
\begin{gathered}
\frac{d}{d r}\left[r^{n-1} f(r) \frac{d \rho}{d r}\right]+r^{n-1}\left[g(r)-\lambda_{\alpha} r^{-2} f(r)\right] \rho=0, \\
\frac{d}{d \theta_{1}}\left[\sin ^{n-2} \theta_{1} \frac{d \varphi}{d \theta_{1}}\right]+\lambda_{\alpha} \varphi \sin ^{n-2} \theta_{1}=0
\end{gathered}
$$

respectively. For $0<\alpha<\pi$, we choose $\lambda_{\alpha}$ to be the smallest number for which (6) has a nontrivial solution $\varphi$ on $0 \leqq \theta_{1} \leqq \alpha$ satisfying $\varphi(\alpha)=0$. It is well-known [2] that $\lambda_{\alpha}$ exists as the smallest eigenvalue of a singular Sturm-Liouville problem. To be specific, we shall suppose that the corresponding eigenfunction has been normalized by the condition $\varphi(0)=1$. For $\alpha=\pi$, we choose $\lambda_{\alpha}=0$ and $\varphi\left(\theta_{1}\right) \equiv 1$. 
THEOREM 1. Equation (1) is oscillatory in $R$ if $R$ contains a cone $C_{\alpha}(\alpha>0)$, and $\left(a_{i j}\right), b$ have majorants $f, g$, respectively, such that

( 7 ) $\quad \int_{1}^{\infty} \frac{d r}{r^{n-1} f(r)}=+\infty$ and $\int_{1}^{\infty} r^{n-1}\left[g(r)-\lambda_{\alpha} r^{-2} f(r)\right] d r=+\infty$.

THEOREM 2. Equation (1) is oscillatory in $R$ if $R$ contains a cone $C_{\alpha}(\alpha>0)$, and $\left(a_{i j}\right), b$ have majorants $f, g$, respectively, such that

$$
\int_{1}^{\infty} \frac{d r}{r^{n-1} f(r)}<\infty \quad \text { and } \quad \int_{1}^{\infty} r^{n-1} h_{n}^{m}(r)\left[g(r)-\lambda_{\alpha} r^{-2} f(r)\right] d r=+\infty,
$$

for some number $m>1$, where $h_{n}(r)=\int_{r}^{\infty} d t / t^{n-1} f(t)$.

Theorem 3. Suppose that $R$ contains the cone $C_{\alpha}$ for some $\alpha>0$, and that $\wedge(x)$ is bounded in $R$. Then equation (1) is oscillatory in $R$ for $n=2$ if

$$
\int_{1}^{\infty} r\left[g(r)-\lambda_{\alpha} r^{-2} f(r)\right] d r=+\infty,
$$

and for $n \geqq 3$ if there exists a number $\delta>0$ such that

$$
\int_{1}^{\infty} r^{1-\delta}\left[g(r)-\lambda_{\alpha} r^{-2} f(r)\right] d r=+\infty,
$$

where $g(r)$ is given by (2).

In the case $n=1,(1)$ is oscillatory if (10) holds with $\delta=1$ (Leighton-Wintner theorem).

THEOREM 4. Suppose that $R$ contains the cone $C_{\alpha}$ for some $\alpha>0$, and that $\wedge(x)$ is bounded in $R$, say $\wedge(x) \leqq \wedge_{1}, x \in R$. Then equation (1) is oscillatory in $R$ if

$$
\lim _{r \rightarrow \infty} \inf r^{2} g(r)>\wedge_{1}\left[\lambda_{\alpha}+(n-2)^{2} / 4\right] .
$$

In particular, (11) reduces to Glazman's criterion [5]

$$
\lim _{r \rightarrow \infty} \inf r^{2} g(r)>(n-2)^{2} / 4
$$

if $-L$ is the Schrödinger operator $-\nabla^{2}-b(x), x \in E^{n}$. For $n=1$ and $a_{11}(x)=1$, Theorem 4 reduces to the classical Kneser-Hille theorem [6]. 
THEOREM 5. Suppose that $L$ is uniformly elliptic in $R_{\text {s }}$ for some $s>0$, i.e., there exists a number $\wedge_{0}>0$ such that $\sum_{i, j} a_{i j}(x) z^{i} z^{j} \geqq \wedge_{0}|z|^{2}$ for all $x \in R_{s}, z \in E^{n}$. Let $g_{0}(r)$ denote the maximum of $b(x)$ for $x \in S_{r}$, $0<r<\infty$. Then equation (1) is nonoscillatory in $R$ if

$$
\lim _{r \rightarrow \infty} \sup r^{2} g_{0}(r)<(n-2)^{2} \wedge_{0} / 4
$$

Proofs. The hypotheses (7) imply that the ordinary differential equation (5) is oscillatory in $0<r<\infty$ by the Leighton-Wintner oscillation theorem $[8,13]$. Let $\rho(r)$ be a nontrivial solution of (5) with zeros at $r=\delta_{1}, \delta_{2}, \cdots$, where $\delta_{k} \uparrow \infty$. If $\phi$ is an eigenfunction of (6) with boundary condition $\varphi(\alpha)=0$ corresponding to the eigenvalue $\lambda_{\alpha}$, the function $v$ defined by (4) is a solution of the comparison equation (3) with nodal domains in the form of "truncated cones"

$$
\begin{gathered}
C_{\alpha k}=\left\{x \in E^{n}: x^{n}>|x| \cos \alpha, \delta_{k}<|x|<\delta_{k+1}\right\}, \\
0<\alpha<\pi, \quad k=1,2, \cdots,
\end{gathered}
$$

with piecewise smooth boundaries.

Thus $v$ has a nodal domain $C_{\alpha k} \subset R_{p}$ for all $p>0$; in fact, for arbitrary $p>0$, choose $k$ large enough so that $\delta_{k} \geqq p$, and clearly $x \in C_{\alpha k}$ implies that $|x|>\delta_{k} \geqq p$ and $x \in C_{\alpha} \subset R$, so that $x \in R_{p}$. Since

$$
\sum_{i, j=1}^{n} a_{i j}(x) z^{i} z^{j} \leqq \wedge(x)|z|^{2} \leqq f(r)|z|^{2}=A(x)|z|^{2}, \quad z \in E^{n},
$$

and $b(x) \geqq g(|x|)=B(x)$, equation (1) majorizes equation (3). It then follows from a known comparison theorem [11, p. 514] that the smallest eigenvalue $\mu$ of the problem

$$
\text { - } L w=\mu w \text { in } C_{\alpha k}, \quad w=0 \text { on } \partial C_{\alpha k}
$$

satisfies $\mu \leqq 0$. Let $M_{\alpha k t}=\left\{x \in C_{\alpha k}: \hat{\delta}_{k}<|x|<t\right\}, \delta_{k}<t \leqq \delta_{k+1}$, and let $\mu(t)$ denote the smallest eigenvalue of the problem

$$
-L w=\mu(t) w \text { in } M_{\alpha k t}, \quad w=0 \text { on } \partial M_{\alpha k t} .
$$

Since $\mu(t)$ is monotone nonincreasing in $\delta_{k}<t \leqq \delta_{k+1}[3]$, and since $\mu\left(\delta_{k+1}\right) \leqq 0$ and $\lim _{t \rightarrow \delta_{k}+} \mu(t)=+\infty$, there exists a number $T$ in $\left(\delta_{k}, \delta_{k+1}\right]$ such that $\mu(T)=0$. This means that $M_{\alpha k T}$ is a nodal domain of a nontrivial solution $u_{k}$ of (1), and since $M_{\alpha k T} \subset C_{\alpha k} \subset R_{p}$ for arbitrary $p>0$ provided $k$ is sufficiently large, equation (1) is oscillatory in $R$. This completes the proof of Theorem 1.

To prove Theorem 2, we use Moore's oscillation theorem [10, p. 127] to deduce that the ordinary differential equation (5) is oscil- 
latory in $0<r<\infty$ on account of the hypotheses (8). The remainder of the proof follows that of Theorem 1 without change.

If $\wedge(x)$ is bounded in $R$, say $\wedge(x) \leqq \wedge_{1}, x \in R$, we can choose $f(r)=\wedge_{1}, 0 \leqq r<\infty$. Then, for $n=2$, the first condition (7) is fulfilled and hence the first statement of Theorem 3 follows from Theorem 1. For $n \geqq 3$, the first condition (8) is fulfilled, and $h_{n}(r)=$ $r^{2-n} /(n-2) \wedge_{1}$. By hypothesis there exists a number $\delta>0$ such that (10) holds. Let $m=1+\delta /(n-2)$. Then one easily checks that the condition (10) implies the second condition (8), and hence the second statement of Theorem 3 follows from Theorem 2.

The hypothesis (11) of Theorem 4 implies that there exist constants $r_{0}$ and $\gamma$ such that

$$
r^{2} g(r)>\gamma>\wedge_{1}\left[\lambda_{\alpha}+(n-2)^{2} / 4\right]
$$

provided that $r>r_{0}$. We then compare (5) with the Euler equation

$$
\frac{d}{d r}\left[\wedge_{1} r^{n-1} \frac{d \rho}{d r}\right]+\left(\gamma-\wedge_{1} \lambda_{\alpha}\right) r^{n-3} \rho=0,
$$

with solutions $\rho=r^{\beta}$, where $\beta$ satisfies

$$
\beta^{2}+(n-2) \beta+\gamma / \wedge_{1}-\lambda_{\alpha}=0 .
$$

Since $\gamma>\wedge_{1}\left[\lambda_{\alpha}+(n-2)^{2} / 4\right]$, equation (13) is oscillatory in $\left(r_{0}, \infty\right)$. Then also (5) is oscillatory by Sturm's comparison theorem on account of the hypotheses

$$
f(r)=\wedge_{1}, \quad r^{n-1}\left[g(r)-\lambda_{\alpha} r^{-2} f(r)\right]>\left(\gamma-\wedge_{1} \lambda_{\alpha}\right) r^{n-3} .
$$

The proof of Theorem 4 is now completed in the same way as that of Theorem 1.

To prove Theorem 5, suppose to the contrary that (1) is oscillatory in $R$. Under the stated hypotheses, it is easily checked that (1) is majorized by the equation

$$
\sum_{i=1}^{n} \wedge_{0} D_{i}^{2} v+B_{0}(x) v=0 \quad\left(B_{0}(x)=g_{0}(|x|), x \in R\right),
$$

and hence there exists a nodal domain $N_{r} \subset R_{r}$ of some nontrivial solution of (14) for all $r>0$ (by an argument similar to that used in the proof of Theorem 1). Then every solution of (14) vanishes at some point of $N_{r} \cup \partial N_{r}$ by the $n$-dimensional analogue of Sturm's separation theorem [1]. However, (14) has radial solutions $v(x)=\rho(r)$ $(r=|x|)$, where $\rho$ satisfies the ordinary differential equation (the analogue of (5)) 


$$
\wedge_{0} \frac{d}{d r}\left(r^{n-1} \frac{d \rho}{d r}\right)+r^{n-1} g_{0}(r) \rho=0 .
$$

The hypothesis (12) implies that there exist constants $r_{0}$ and $\gamma$ such that

$$
r^{2} g_{0}(r)<\gamma<(n-2)^{2} \wedge_{0} / 4
$$

for $r>r_{0}$. Thus the Euler equation

$$
\wedge_{0} \frac{d}{d r}\left(r^{n-1} \frac{d \rho}{d r}\right)+\gamma r^{n-3} \rho=0
$$

is nonoscillatory, and also (15) is nonoscillatory by Sturm's comparison theorem. This means that there exists a solution $v(x)=\rho(r)$ of (14) and a number $r_{0}$ such that $v(x)$ is free of zeros in $R_{r}$ for all $r>r_{0}$, and the contradiction establishes Theorem 5 .

\section{REFERENCES}

1. C. Clark and C. A. Swanson, Comparison theorems for elliptic differential equations, Proc. Amer. Math. Soc. 16 (1965), 886-890.

2. E. A. Coddington and N. Levinson, Theory of Ordinary Differential Equations, McGraw-Hill, New York, 1955.

3. R. Courant and D. Hilbert, Methods of Mathematical Physics I, Wiley (Interscience), New York, 1953.

4. I. M. Glazman, On the negative part of the spectrum of one-dimensional and multidimensional differential operators on vector-functions, Dokl. Akad. Nauk SSSR (N.S.) 119 (1958), 421-424.

5. —, Direct Methods of Qualitative Spectral Analysis of Singular Differential Operators, Israel Program for Scientific Translations, Daniel Davey and Co., New York, 1965.

6. E. Hille, Non-oscillation theorems, Trans. Amer. Math. Soc. 64 (1948), 234-252.

7. K. Kreith, Oscillation theorems for elliptic equations, Proc. Amer. Math. Soc. 15 (1964), 341-344.

8. W. Leighton, On self-adjoint differential equations of second order, J. London Math. Soc. 27 (1952), 37-47.

9. S. G. Mikhlin, The Problem of the Minimum of a Quadratic Functional, HoldenDay, San Francisco, 1965.

10. R. A. Moore, The behavior of solutions of a linear differential equation of second order, Pacific J. Math. 5 (1955), 125-145.

11. C. A. Swanson, A generalization of Sturm's comparison theorem, J. Math. Anal. Appl. 15 (1966), 512-519.

12. - An identity for elliptic equations with applications, Trans. Amer. Math. Soc. (to appear).

13. A. Wintner, A criterion of oscillatory stability, Quart. Appl. Math. 7 (1949), $115-117$.

Received January 25, 1968. Research sponsored by the Air Force Office of Scientific Research, Office of Aerospace Research, United States Air Force, under grant AF-AFOSR-379-67. 


\section{PACIFIC JOURNAL OF MATHEMATICS}

\section{EDITORS}

\section{H. ROYDEN}

Stanford University

Stanford, California

\section{J. Dugundu}

Department of Mathematics University of Southern California Los Angeles, California 90007

RICHARD ARENS

University of California Los Angeles, California 90024

ASSOCIATE EDITORS
E. F. Beckenbach
B. H. NEUMANN
F. WoLF
K. YosidA

\section{SUPPORTING INSTITUTIONS}

\author{
UNIVERSITY OF BRITISH COLUMBIA \\ CALIFORNIA INSTITUTE OF TECHNOLOGY \\ UNIVERSITY OF CALIFORNIA \\ MONTANA STATE UNIVERSITY \\ UNIVERSITY OF NEVADA \\ NEW MEXICO STATE UNIVERSITY \\ OREGON STATE UNIVERSITY \\ UNIVERSITY OF OREGON \\ OSAKA UNIVERSITY \\ UNIVERSITY OF SOUTHERN CALIFORNIA
}

STANFORD UNIVERSITY

UNIVERSITY OF TOKYO

UNIVERSITY OF UTAH

WASHINGTON STATE UNIVERSITY

UNIVERSITY OF WASHINGTON

AMERICAN MATHEMATICAL SOCIETY
CHEVRON RESEARCH CORPORATION
TRW SYSTEMS

AMERICAN MATHEMATICAL SOCIETY

TRW SYSTEMS

NAVAL WEAPONS CENTER

Mathematical papers intended for publication in the Pacific Journal of Mathematics should be in typed form or offset-reproduced, double spaced with large margins. Underline Greek letters in red, German in green, and script in blue. The first paragraph or two must be capable of being used separately as a synopsis of the entire paper. It should not contain references to the bibliography. Manuscripts, in duplicate if possible, may be sent to any one of the four editors. All other communications to the editors should be addressed to the managing editor, Richard Arens, University of California, Los Angeles, California 90024.

Each author of each article receives 50 reprints free of charge; additional copies may be obtained at cost in multiples of 50 .

The Pacific Journal of Mathematics is published monthly. Effective with Volume 16 the price per volume (3 numbers) is $\$ 8.00$; single issues, $\$ 3.00$. Special price for current issues to individual faculty members of supporting institutions and to individual members of the American Mathematical Society: $\$ 4.00$ per volume; single issues $\$ 1.50$. Back numbers are available.

Subscriptions, orders for back numbers, and changes of address should be sent to Pacific Journal of Mathematics, 103 Highland Boulevard, Berkeley 8, California.

Printed at Kokusai Bunken Insatsusha (International Academic Printing Co., Ltd.), 7-17, Fujimi 2-chome, Chiyoda-ku, Tokyo, Japan.

PUBLISHED BY PACIFIC JOURNAL OF MATHEMATICS, A NON-PROFIT CORPORATION

The Supporting Institutions listed above contribute to the cost of publication of this Journal, but they are not owners of publishers and have no responsibility for its content or policies. 


\section{Pacific Journal of Mathematics \\ Vol. 27, No. 3}

March, 1968

Charles A. Akemann, Invariant subspaces of $C(G) \ldots \ldots \ldots \ldots \ldots \ldots . \ldots 41$

Dan Amir and Zvi Ziegler, Generalized convexity cones and their duals ... . 425

Raymond Balbes, On ( $J, M, \mathrm{~m})$-extensions of order sums of distributive

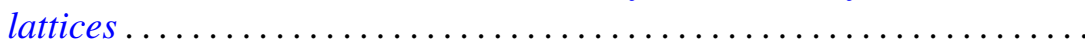

Jan-Erik Björk, Extensions of the maximal ideal space of a function algebra ........................................ 453

Frank Castagna, Sums of automorphisms of a primary abelian group ...... 463

Theodore Seio Chihara, On determinate Hamburger moment problems ..... .

Zeev Ditzian, Convolution transforms whose inversion function has complex

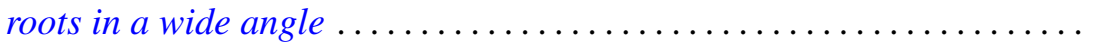

Myron Goldstein, On a paper of Rao .

Velmer B. Headley and Charles Andrew Swanson, Oscillation criteria for

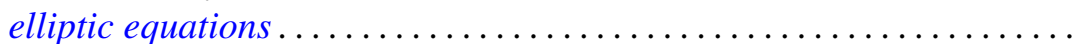

John Willard Heidel, Qualitative behavior of solutions of a third order nonlinear differential equation............................

Alan Carleton Hindmarsh, Pick's conditions and analyticity.............

Bruce Ansgar Jensen and Donald Wright Miller, Commutative semigroups

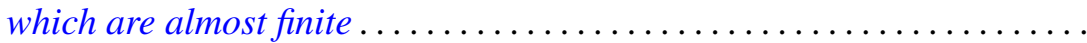

Lynn Clifford Kurtz and Don Harrell Tucker, An extended form of the

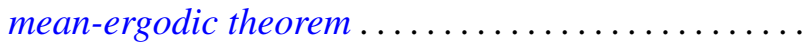

S. P. Lloyd, Feller boundary induced by a transition operator ...

Henry B. Mann, Josephine Mitchell and Lowell Schoenfeld, A new proof of the maximum principle for doubly-harmonic functions ...

Robert Einsohn Mosher, The product formula for the third obstruction ..

Sam Bernard Nadler, Jr., Sequences of contractions and fixed points ...

Eric Albert Nordgren, Invariant subspaces of a direct sum of weighted shifts...

Fred Richman, Thin abelian p-groups ...

Jordan Tobias Rosenbaum, Simultaneous interpolation in $\mathrm{H}_{2}$. II ...

Charles Thomas Scarborough, Minimal Urysohn spaces .

Malcolm Jay Sherman, Disjoint invariant subspaces..... .

Joel John Westman, Harmonic analysis on groupoids....

621

William Jennings Wickless, Quasi-isomorphism and TFM

Minoru Hasegawa, Correction to "On the convergence of resolvents of operators" 